\section{Stop knocking social sciences}

SIR - 'Scientific misconduct' has been much discussed recently, leading at least one commentator to suggest that "the current research environment seems to foster cynicism about simple virtues such as honesty and fairness". Consider a case in point.

I edit a journal, Social Studies of Science, which serves a growing international community of researchers, mainly in the social sciences and humanities, working on a wide range of problems and issues. Many members of this community collaborate closely with scientists and engineers, earning their credibility through effective work in industry and public policy. These individuals have recently come under attack from a number of scientists, mainly in the United States. Authors find their work incompetently summarized and unfairly derided in what one reviewer has described as a "willful strategy of distortion and demonization". Some have been personally insulted, and many are being actively harassed, particularly on US campuses.

In publicity material for a recent conference organized by the New York Academy of Sciences, it is implied that the community's work consists of “arguments advanced by those who would reject reason and take up the cudgels against science". Critics have dismissed their research as "a body of work founded on silly philosophy, sloppy history, anemic research, boundless ignorance, and just plain lousy scholarship", exhibiting "a deeply disapproving stance towards science, sometimes combined with a profound ignorance of it" . Ironically, such intemperate claims are being made in defence of scholarly standards and values.

I cite just two specific examples. Steven Weinberg ${ }^{4}$ misrepresents the work of Edinburgh colleagues (without evidence or citation), with two offensive 'jokes' - one describing the so-called "strong programme" in the field as the "Strong Pogrom", the other referring to "madness" and "nonsense". Elsewhere ${ }^{5}$, a book by two reputable sociologists of science has been dismissed as "largely claptrap, but... attractive to... students looking for an easy path to a degree... just another product of academics on the make... who interpret carefully selected data to fit their prejudices, all to improve their standing in the academy without having to do any intellectual heavy lifting".

Such unscholarly language is unacceptable in intellectual debate. One could, perhaps, brush aside this kind of thing, much as we British feel able to ignore (say) the creationists. However, where individuals expressing such views wield power in the academic world, the possibility of corrupting the scholarly process is real. It should be resisted firmly. Scientists may feel that perceived threats to their 'objectivity' justify crude responses, and abandon all traces of trust, sensitivity and respect among academic colleagues. But such a strategy is counterproductive: far from conserving and extending the 'science and reason' it claims to be defending, it actually demeans and devalues it.

This behaviour is clearly a breach of any guidelines for proper conduct among scientists. One immediate casualty of this tawdry campaign could be the academic credit and insight so painstakingly acquired by our community over some 30 years, and now available to inform and guide progress towards the fuller 'science and reason' demanded by our increasingly complex society. To squander so carelessly what we have learned so patiently would be tragic.

\section{David Edge}

25 Gilmour Road,

Edinburgh EH16 5NS, UK

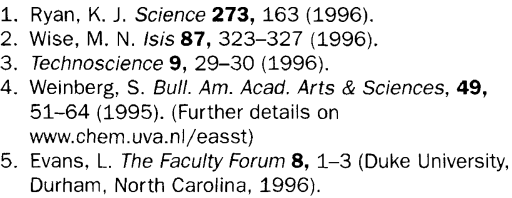

\section{Abstract values}

SIR - The recent survey by Liu and Danziger ${ }^{1}$ was not the first on the fate of conference abstracts. Goldman and Loscal$\mathrm{zo}^{2}$ followed up 276 randomly selected cardiology abstracts, and about half became full-length articles in peer-reviewed journals after 3.5 years. Meranze et al. ${ }^{3}$ looked at anaesthesia abstracts 1-2 years after presentation, and Yentis et al. ${ }^{4}$ did a more extended survey of abstracts from four anaesthesia societies. Again, about half had been published by 3 to 5 years. Scherer $e t$ al. ${ }^{5}$ surveyed abstracts in ophthalmology; about half appeared in full, mostly within 2 years, and there was a weak association between full publication and statistically significant results. Liu and Danziger's figures for their four journals were lower than $50 \%$, though some of their 1992 abstracts are not yet 5 years old.

Articles on this subject can be found in Medline by searching on the word 'abstract' as a title word, and then using the terms 'abstracting and indexing', 'congresses' and 'time factors'.

\section{Neville W. Goodman}

Department of Anaesthesia,

Southmead Hospital,

Bristol BS10 5NB, UK

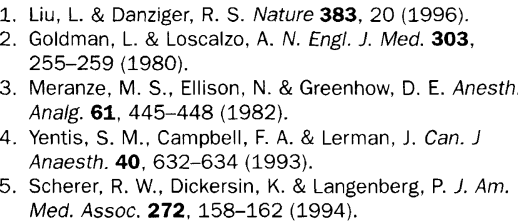

\section{No miracle}

SIR - Your reports on the production of 'herbal petrol' by Ramar Pillai of Tamil Nadu in India may have given the impression that his claim has been substantiated (Nature 383, 112; 1996). Not only is that not true, but it is clear that he is a hoaxer, and that the petrol he has been producing in his demonstrations did not come from a plant.

Pillai has been making his claim for some time but, whenever experiments have been carried out under controlled conditions, they have been total failures. The first such experiment was in early 1995 at the Centre for Policy Studies in Madras, when Pillai apparently abandoned his equipment and disappeared. The second was carried out a few weeks ago under the supervision of Professor V. S. Ramamurthy, secretary of the Department of Science and Technology of the Government of India, and was again a disaster for Pillai, with not a drop of petrol forthcoming; he was caught trying to introduce commercial petrol into the system on the sly (see Nature 383, 269; 1996).

A large number of reports have since appeared in Indian newspapers expressing doubts about Pillai's claims, as well as providing a reason for his deceit. There have been large-scale thefts of petrol from tankers in and around the area in which Pillai lives, and the strategy seems to have been to sell this petrol on the open market as 'herbal petrol'. It is widely believed that individuals with political links have been involved, knowing that they could exploit the gullibility of the many people, including scientists, prepared to believe in miracles.

\section{Pushpa M. Bhargava}

Anveshna Consultancy Services,

12-13-414/4 Street No. 1,

Tarnaka, Hyderabad 500 017, India

\section{Spanish practice}

SIR - J. T. C. Sellick (Nature 383, 569; 1996) asks how to keep two surnames when authoring a paper. He complains about all sorts of combinations made by indexing databases which, being accustomed to handling only one-surnamed authors, find it difficult to consider other possibilities.

In Spain we have two surnames inherited from each of our parents and we all have similar problems when deciding what will be the 'scientific name' that will be used to author a paper. Some people, like myself, settle on only one surname, usually the less common one, but those who wish to keep both surnames resort to using a hyphen between them. This option seems to keep journal editors and database curators happy. I therefore suggest to J. T. Clark Sellick that he changes his name to J. T. Clark-Sellick.

\section{Luis M. Corrochano}

Departmento de Genetica,

Universidad de Sevilla,

Apartado 1095, E-41080 Sevilla, Spain 